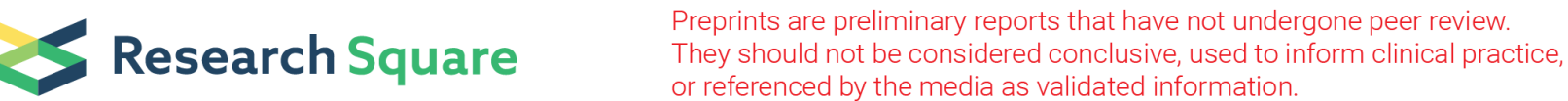

\section{Development and Validation of a Decisional Balance Tool to Assess Perceived Benefits and Barriers of Vegetable Consumption in Adults}

\section{Yaeko Kawaguchi}

Kokuritsu Byoin Kiko Kyoto Iryo Center

Junichiro Somei

Kokuritsu Byoin Kiko Kyoto Iryo Center

Chikana Kawaguchi

Tohoku Daigaku

Akiko Suganuma

Kokuritsu Byoin Kiko Kyoto Iryo Center

Shinsuke Nirengi

Kokuritsu Byoin Kiko Kyoto Iryo Center

Naoki Sakane ( $\nabla$ nsakane@gf6.so-net.ne.jp )

National Hospital Organization Kyoto Medical Center https://orcid.org/0000-0002-2625-571X

\section{Research}

Keywords: vegetable consumption, questionnaire, perceived benefits and barriers, decisional balance

Posted Date: June 25th, 2020

DOI: https://doi.org/10.21203/rs.3.rs-37046/v1

License: () (1) This work is licensed under a Creative Commons Attribution 4.0 International License. Read Full License 


\section{Abstract}

Background: The aim of this study was to develop and validate a decisional balance tool for assessing the perceived benefits and barriers of vegetable intake in adults.

Methods: Our study comprised 379 adults aged $20-70$ years (mean age: $30.5 \pm 12.6$ years; men: $21.4 \%$ ). Data (demographic parameters, vegetable intake, stage of change) were collected via a web-based survey. The decisional balance score was calculated by subtracting the score for perceived barriers from the score for perceived benefits.

Results: The final 24 items in our questionnaire had a two-domain ("pleasure" and "healthy" for perceived benefits) or three-domain ("not attractive," "low priority," and "hard to get" for perceived barriers) structure with high internal consistency (Cronbach's alpha: $0.82,0.79,0.82,0.76$, and 0.76 , respectively). The intraclass correlation coefficient in a test-retest reliability study was high (0.77). The decisional balance score positively correlated with the number of vegetable servings as the external parameter (Spearman's correlation: $0.461 ; \mathrm{P}<0.001)$.

Conclusions: Our questionnaire is a valid and reliable tool for assessing the pros and cons of vegetable consumption in adults.

\section{Background}

Vegetable intake has widely accepted health benefits, including the prevention of diabetes, hypertension, cancer, stroke, cardiovascular disease, and a reduction in all-cause mortality [1-3]. It is a commonly recommended, non-pharmacological intervention, and is endorsed by most countries [4]; however, many individuals do not consume enough vegetables to reap the benefits. The " 5 -a-day" message is simple and encourages people in the UK to eat more fruits and vegetables [5]. In Japan, the recommended daily intake of vegetables is $350 \mathrm{~g}$ or more, which exceeds that of fruits $(200 \mathrm{~g})$ [6]. The National Health and Nutrition Survey in 2018 revealed that only approximately 30\% of Japanese people (men: $30.7 \%$; women: $27.0 \%$ ) over 20 years of age eat five or more servings (SVs) of vegetables per day [7]. A standard serving of vegetables is $70 \mathrm{~g}$ in Japan; therefore, five servings is equal to $350 \mathrm{~g}$ per day. The decisional balance tool is a promotional tool that weighs the perceived pros (benefits) and cons (barriers) of a specific behavior [8]. In ambivalent people, interventions affecting decisional balance tend to hinder commitment to change [9]. There are several studies about decisional balance tools for vegetable intake. Shtaynberger and Krebs reported that fruit and vegetable consumption was significantly associated with decisional balance pros, but not cons among 86 adult cancer survivors [10]. Wang et al. reported that fruit intake, but not vegetable consumption, was negatively correlated with high perceived barriers to consumption [11]. Chuan et al. reported that pros scores positively correlated (Spearman correlation $=0.24$ ) and con scores weakly negatively correlated (Spearman correlation $=-0.10$ ) with daily servings of vegetables [12]. Therefore, a decisional balance tool with external validity is required to assess the pros and cons of vegetable consumption. The aim of this study was to develop and validate a decisional balance tool, 
matched to the stage of change, to help diet consultants identify ways to increase vegetable consumption in Japanese adults.

\section{Methods}

\section{Participants and the web-based survey}

Study participants were recruited between September 2017 and January 2018 from university and vocational school student cohorts majoring in nutrition, medical staff, local area residents, and from personal networks from several regions of Japan. A total of 398 individuals responded to a web-based survey. Nineteen respondents were excluded as they did not meet the lower age limit of at least 20 years. The final number of adults enrolled in this study was 379 .

The web-based survey was a self-administered questionnaire that assessed demographic parameters (age, body mass index, marital status, employment status, household income, residential situation), vegetable intake per meal (breakfast, lunch, dinner, snack), stage of change (precontemplation, contemplation, preparation, action/maintenance), decisional balance (perceived benefits and barriers), the importance of vegetable intake, and confidence (self-efficacy) in eating five SVs of vegetables per day.

The study protocol conformed to the ethical guidelines of the Helsinki Declaration, and the study design was approved by the ethics committee of Kyoto Medical Center (18-095). Informed consent was obtained from all participants prior to starting the survey.

\section{Factor Analysis}

The questionnaire was evaluated by five dietitians and three researchers to assess clarity and was modified on the basis of their comments.

After careful consideration of the input from the experts, and an examination of the existing scales, an exploratory factor analysis was performed. Its purpose was to assess the validity of the items in the questionnaire and to identify the factors that group the items. The questionnaire initially included 15 items related to perceived benefits and 15 items related to perceived barriers. Each item was scored on a 5-point Likert-like scale ranging from "strongly disagree" (1 point) to "strongly agree" (5 points).

The factor analysis involved Promax rotation of the retained items. Promax rotation maximizes the sum of the variance of the squared loadings, where loading is defined as the correlation between the item and the factor. It highlights a small number of key items, which simplifies the interpretation of the results. Interpretation of the rotated value involves the identification of the items loaded on each retained factor, the determination of the conceptual meaning of the items loaded on the same factor, and the conceptual differences between the items loaded on different factors. The relationship of each item to the underlying 
factor is expressed by the rotated factor loading value. Pattern loadings with an absolute value of approximately 0.35 or more were used to interpret the results.

\section{Internal Validity}

The items assessing perceived benefits and perceived barriers were tested for construct validity using the Kaiser-Meyer-Olkin (KMO) test. A KMO value of approximately 1 is good, and a value of 0.6 is acceptable. Items with $\mathrm{KMO}$ values $<0.5$ (which indicates low communality) can usually be excluded from the analysis [13]. The reliability of the questionnaire was evaluated using Cronbach's alpha coefficient [14], which scores internal consistency as follows: $<0.5$, unacceptable; 0.5 to $<0.6$, poor; 0.6 to $<0.7$, questionable; 0.7 to $<0.8$, acceptable; 0.8 to $<0.9$, good; and $\geq 0.9$, excellent.

\section{External Validity}

Regarding the stage of change for vegetable intake, $10.6 \%$ of the participants were in precontemplation, $63.6 \%$ were in contemplation, $8.7 \%$ in preparation, and $17.1 \%$ in action/maintenance. The numbers of SVs for the stages were 2.04, 2.23, 2.67, and 4.22, respectively ( $P$ for trend $<0.001$ ). For each meal except snacks, vegetable intake increased across the stages $(P$ for trend $<0.001)$ (Table 2$)$.

Figure 2. Pros and cons T-scores by stage of change.

The scores were presented as standardized T-scores (mean $=50, S D=10)$. 
Table 2

Vegetable Intake and Decisional Balance Score by Stage of Changes

\begin{tabular}{|c|c|c|c|c|c|c|}
\hline Stage of changes & $\begin{array}{l}\text { All } \\
(n=379)\end{array}$ & $\begin{array}{l}\text { PC } \\
(n=40)\end{array}$ & $\begin{array}{l}C \\
(n=241)\end{array}$ & $\begin{array}{l}P \\
(n=33)\end{array}$ & $\begin{array}{l}A / M \\
(n=65)\end{array}$ & $p$ \\
\hline \multicolumn{7}{|c|}{ Vegetable intake, SV } \\
\hline Breakfast & $\begin{array}{l}0.36 \\
(0.48)\end{array}$ & $\begin{array}{l}0.19 \\
(0.29)\end{array}$ & $\begin{array}{l}0.26 \\
(0.38)\end{array}$ & $\begin{array}{l}0.41 \\
(0.46)\end{array}$ & $\begin{array}{l}0.78 \\
(0.63)\end{array}$ & $<.001$ \\
\hline Lunch & $\begin{array}{l}0.84 \\
(0.58)\end{array}$ & $\begin{array}{l}0.81 \\
(0.55)\end{array}$ & $\begin{array}{l}0.73 \\
(0.53)\end{array}$ & $\begin{array}{l}0.89 \\
(0.46)\end{array}$ & $\begin{array}{l}1.24 \\
(0.64)\end{array}$ & $\begin{array}{l}< \\
0.001\end{array}$ \\
\hline Dinner & $\begin{array}{l}1.35 \\
(0.79)\end{array}$ & $\begin{array}{l}1.04 \\
(0.58)\end{array}$ & $\begin{array}{l}1.20 \\
(0.68)\end{array}$ & $\begin{array}{l}1.33 \\
(0.55)\end{array}$ & $\begin{array}{l}2.11 \\
(0.95)\end{array}$ & $\begin{array}{l}<.001 \\
0.001\end{array}$ \\
\hline Snack & $\begin{array}{l}0.05 \\
(0.19)\end{array}$ & $\begin{array}{l}0.00 \\
(0.00)\end{array}$ & $\begin{array}{l}0.04 \\
(0.18)\end{array}$ & $\begin{array}{l}0.03 \\
(0.12)\end{array}$ & $\begin{array}{l}0.10 \\
(0.28)\end{array}$ & 0.013 \\
\hline Total / Day & $\begin{array}{l}2.59 \\
(1.46)\end{array}$ & $\begin{array}{l}2.04 \\
(1.12)\end{array}$ & $\begin{array}{l}2.23 \\
(1.21)\end{array}$ & $\begin{array}{l}2.67 \\
(0.93)\end{array}$ & $\begin{array}{l}4.22 \\
(1.55)\end{array}$ & $\begin{array}{l}< \\
0.001\end{array}$ \\
\hline $\begin{array}{l}\text { Benefits (pros), } \\
\text { points }\end{array}$ & $\begin{array}{l}4.00 \\
(0.60)\end{array}$ & $\begin{array}{l}3.66 \\
(0.62)\end{array}$ & $\begin{array}{l}3.95 \\
(0.59)\end{array}$ & $\begin{array}{l}4.16 \\
(0.42)\end{array}$ & $\begin{array}{l}4.32 \\
(0.52)\end{array}$ & $\begin{array}{l}<.001 \\
0.001\end{array}$ \\
\hline & $\begin{array}{l}3.92 \\
(0.71)\end{array}$ & $\begin{array}{l}3.55 \\
(0.74)\end{array}$ & $\begin{array}{l}3.85 \\
(0.71)\end{array}$ & $\begin{array}{l}4.12 \\
(0.48)\end{array}$ & $\begin{array}{l}4.31 \\
(0.58)\end{array}$ & $\begin{array}{l}< \\
0.001\end{array}$ \\
\hline Healthy & $\begin{array}{l}4.08 \\
(0.61)\end{array}$ & $\begin{array}{l}3.77 \\
(0.64)\end{array}$ & $\begin{array}{l}4.04 \\
(0.62)\end{array}$ & $\begin{array}{l}4.21 \\
(0.48)\end{array}$ & $\begin{array}{l}4.33 \\
(0.52)\end{array}$ & $\begin{array}{l}< \\
0.001\end{array}$ \\
\hline $\begin{array}{l}\text { Barriers (cons), } \\
\text { points }\end{array}$ & $\begin{array}{l}2.57 \\
(0.76)\end{array}$ & $\begin{array}{l}2.94 \\
(0.61)\end{array}$ & $\begin{array}{l}2.67 \\
(0.72)\end{array}$ & $\begin{array}{l}2.43 \\
(0.71)\end{array}$ & $\begin{array}{l}2.02 \\
(0.77)\end{array}$ & $\begin{array}{l}< \\
0.001\end{array}$ \\
\hline Total score & $\begin{array}{l}2.81 \\
(0.82)\end{array}$ & $\begin{array}{l}3.16 \\
(0.64)\end{array}$ & $\begin{array}{l}2.92 \\
(0.77)\end{array}$ & $\begin{array}{l}2.69 \\
(0.82)\end{array}$ & $\begin{array}{l}2.27 \\
(0.88)\end{array}$ & $\begin{array}{l}< \\
0.001\end{array}$ \\
\hline $\begin{array}{l}\text { Not attractive } \\
\text { Low priority }\end{array}$ & $\begin{array}{l}2.16 \\
(0.96)\end{array}$ & $\begin{array}{l}2.56 \\
(0.93)\end{array}$ & $\begin{array}{l}2.26 \\
(0.97)\end{array}$ & $\begin{array}{l}2.10 \\
(0.88)\end{array}$ & $\begin{array}{l}1.58 \\
(0.76)\end{array}$ & $\begin{array}{l}< \\
0.001\end{array}$ \\
\hline Hard to get & $\begin{array}{l}2.30 \\
(1.09)\end{array}$ & $\begin{array}{l}2.75 \\
(1.19)\end{array}$ & $\begin{array}{l}2.40 \\
(1.09)\end{array}$ & $\begin{array}{l}2.02 \\
(0.91)\end{array}$ & $\begin{array}{l}1.79 \\
(0.94)\end{array}$ & $\begin{array}{l}< \\
0.001\end{array}$ \\
\hline
\end{tabular}

Values are the mean (S.D.). The decisional balance score consisted of twelve pro and twelve con items scored from 1 to 5. PC (precontemplation, $n=40$ ), C (contemplation, $n=241$ ), $P$ (preparation, $n=33$ ), A/M (action/maintenance, $\mathrm{n}=65$ ).

At each stage, there was a significant difference between the T-scores for the pro items and con items (Fig. 2).

The decisional balance score (the pro score minus the con score) was 0.72 for precontemplation, 1.28 for contemplation, 1.73 for preparation, and 2.30 for action/maintenance ( $P$ for trend $<0.001)$. It increased in both pro domains and decreased in all three con domains across the stages $(P$ for trend $<0.001)$ and 
positively correlated with vegetable consumption (Spearman's correlation: $0.461 ; P<0.001$ ). The number of vegetable SVs was directly proportional to the perceived benefits score and inversely proportional to the perceived barriers score (Spearman's correlation: 0.324 and 0.435, respectively). Higher vegetable consumption correlated with lower perceived barriers scores (odds ratio: $0.42 ; 95 \% \mathrm{Cl}: 0.26,0.68$ ) and higher perceived benefits scores (odds ratio: $2.75 ; 95 \% \mathrm{Cl}: 1.40,5.40$ ).

For each increase in the number of vegetable SVs, the pros score increased by 0.76 (standard error: 0.12 ), whereas the cons score decreased by 0.77 (standard error: 0.09). Interestingly, the effect sizes for the pro and con items were similar (Hedges' g: 1.18 and 1.29, respectively).

\section{Reliability Testing}

Intraclass correlation coefficients (ICCs) with 95\% confidence intervals (Cls) were used to assess testretest reliability by comparing the participants' responses to the questions at two time points. The interval between the test and retest was at least one week but less than four weeks. The ICCs were calculated using a 2-way mixed model based on absolute agreement. Agreement was rated as suggested by Landis and Koch [18] as follows: $<0.00$, poor; $0.00-0.20$, slight; $0.21-0.40$, fair; $0.41-0.60$, moderate; $0.61-0.80$, substantial; and $0.81-1.00$, almost perfect.

\section{Statistical Analysis}

Each of the final 12 items in the pro and con categories was summed and standardized using T-scores for ease of reporting. A trend analysis was used to examine the relationship of decisional balance to the stage of change. Cronbach's alpha coefficient was used to determine the reliability of the factors (internal consistency). ICCs were used to evaluate reproducibility. P values $<0.05$ were considered significant. Hedges' $\mathrm{g}$ was used to categorize effect sizes as small, medium, or large $(\mathrm{g}=0.20,0.50$, and 0.80 , respectively). All statistical analyses were performed using SPSS for Windows (IBM SPSS Statistics, ver. 20.0).

\section{Results}

\section{Characteristics of the participants}

Our study comprised 379 adults aged $20-70$ years (mean age: $30.5 \pm 12.6$ years; men: $21.4 \%$ ) with a mean body mass index of $21.0 \pm 2.8 \mathrm{~kg} / \mathrm{m}^{2}$. More than two-thirds were single $(71.2 \%)$, although most lived with their families or others $(67.3 \%)$. The annual household income was low ( $<2$ million yen) in $4.0 \%$, middling ( $>2$ to $<6$ million yen) in $24.5 \%$, high ( $>6$ million yen) in $31.7 \%$, and unknown in $39.8 \%$. The number of vegetable SVs per day was $2.59 \pm 1.46$; per meal it was $0.36 \pm 0.48$ (breakfast), $0.84 \pm 0.58$ (lunch), $1.35 \pm 0.79$ (dinner), and $0.05 \pm 0.19$ (snack). 
Overall, 237 participants (62.5\%) were aware of the current recommendations for vegetable intake. Awareness of the importance of, and confidence (self-efficacy) in, eating five SVs of vegetables per day at each stage of change are shown in Supplemental Table S1. Both parameters differed significantly across the stage of change spectrum in a trend analysis $(P<0.05)$.

\section{Factor analysis}

Exploratory factor analysis using the Promax rotation was performed to verify construct validity and to determine the factor structure of the benefits and barriers. Six items (three for perceived benefits and three for perceived barriers) were excluded from the questionnaire owing to a factor loading value $<0.35$. For perceived benefits, the excluded items were "I feel guilty if I don't eat vegetables," "Eating vegetables pleases my family," and "I drink vegetable juice as a part of meal every day" (questions 4, 10, and 15 on the questionnaire, respectively). For perceived barriers, they were "I don't know what vegetables I should buy," "Eating vegetables takes time," and "I don't have utensils for cooking vegetables" (questions 1, 5, and 10 respectively). The final 24 items had either a 2-domain structure ("pleasure" and "healthy" for perceived benefits) or a 3-domain structure ("not attractive," "low priority," and "hard to get" for perceived barriers).

\section{Internal validity}

The KMO values for the 12 items in the perceived benefits category and the 12 items in the perceived barriers category were good ( 0.887 and 0.876 , respectively). The two domains for perceived benefits (Cronbach's alpha: 0.82 and 0.79 , respectively) and the three domains for perceived barriers (Cronbach's alpha: $0.82,0.76$, and 0.76 , respectively) had high internal consistency (Table 1 ). 
Table 1

Factors and factor loading values for vegetable intake

Pros : Perceived benefits (Cronbach's $a=0.87$ )

Factor loading

Pleasure (Cronbach's $a=0.82$ )

$9 \quad$ Eating fresh vegetables makes me feel better.

0.79

3 Vegetables are delicious.

0.77

8 Eating seasonal vegetables puts me in touch with the season.

0.71

14 A variety of vegetables makes eating enjoyable.

0.69

2 Eating vegetables refreshes my mouth.

0.51

5 I feel full after eating vegetables.

Healthy (Cronbach's $a=0.79$ )

$7 \quad$ Eating vegetables improves my appearance (especially my skin condition). $\quad 0.75$

12 Eating vegetables helps me stay healthy.

0.75

13 Vegetables are healthy because of low energy density.

0.60

$6 \quad$ Eating vegetables aids bowel movements.

0.48

1 Eating vegetables maintains a good physical condition.

0.40

11 Dishes with vegetables look appealing and colorful.

0.40

Cons : Perceived barriers (Cronbach's $\mathrm{a}=\mathbf{0 . 8 7}$ )

Factor loading

Not attractive (Cronbach's $a=0.82$ )

$8 \quad$ Vegetables are boring because of limited cooking methods. 0.73

$3 \quad$ Vegetables do not last long and cannot be used up well. 0.66

9 Cooking preparation for vegetables is time-consuming. 0.65

6 It is difficult to buy the right amount of vegetables. 0.59

11 The vegetables I cook myself are not tasty. $\quad 0.47$

13 Buying vegetables is not economical. $\quad 0.40$

$\begin{array}{lll}7 & \text { I do feel satisfied after eating vegetables. } & 0.39\end{array}$

\section{Low priority (Cronbach's $a=0.76$ )}

14 I do not eat vegetables when I have a late dinner.

0.82

15 I do not eat vegetables when I am tired.

0.73 
12 I do not eat vegetables if there are other choices more to my liking.

0.50

Hard to get (Cronbach's $a=0.76$ )

$4 \quad$ It is difficult to go to stores to buy vegetables.

0.79

2 I do not have time to buy or obtain vegetables.

0.70

The factor analysis was performed using the maximum likelihood method with Promax rotation of the items in the benefits and barriers categories.

\section{Test-retest Reliability}

The test-retest reliability study had a high ICC (0.77).

\section{Discussion}

We developed and validated a decisional balance tool to assess the perceived benefits and barriers of vegetable intake in adults. Our questionnaire had 24 items in two domains ("pleasure" and "healthy" for perceived benefits) or three domains ("not attractive," "low priority," and "hard to get" for perceived barriers) with high internal consistency. Our scales exhibited acceptable internal consistency reliabilities. The Cronbach's alpha coefficients were $0.76-0.87$, which is within the range previously reported for pro and con items and process of change measurements in adults $[18,19]$.

The questionnaire prepared by Wang et al. had 16 items and five domains for perceived barriers ("economic/distribution factors," "family and self-preference," "availability when eating outside the home," "personal judgment and awareness," and "personal habits"), with Cronbach's alpha coefficients ranging from 0.57 to 0.84 [11]. In that study, perceived barriers were not associated with vegetable consumption. In contrast, our study showed a negative correlation between perceived barriers and vegetable consumption (odds ratio: $0.42 ; 95 \% \mathrm{Cl}: 0.26,0.68$ ). Our study also revealed a positive correlation between perceived benefits and vegetable consumption (odds ratio: $2.75 ; 95 \% \mathrm{Cl}: 1.40,5.40$ ). Hence, our scale is useful for assessing the relationship between perceived benefits and barriers and vegetable intake.

In our study, the decisional balance score varied across the stages of change, which is consistent with the findings of previous studies [20,21]. Our participants had higher pro scores and lower con scores in the later stages than in the earlier stages of change. For vegetable consumption, the perceived benefits began to outweigh the perceived barriers between the contemplation and preparation stages (Fig. 2).

The principal-component analysis by Chuan et al. revealed the two components that best represented the benefits (Cronbach's alpha: 0.86 ) and barriers (Cronbach's alpha: 0.79$)$ of fruit and vegetable consumption [12]. They also reported that the pro and con scores crossed over between the 
contemplation and preparation stages and that the increase in the pros scores across the stages corresponded to a medium effect size, whereas the decrease in cons scores corresponded to a small effect size. In our study, for each increase in the number of SVs, the pros score increased by 0.76 , whereas the cons score decreased by 0.77 . The effect sizes for the pros and cons items were similar (Hedges' g: 1.18 and 1.29, respectively). Therefore, our scale is useful for assessing decisional balance.

This study has some limitations. First, it included only Japanese adults. Further investigation is required to determine whether our results can be extended to other ethnic groups and children. Moreover, it will be important to examine the willingness to eat vegetables at an earlier age. Second, we did not consider the stage of change or decisional balance variations for different vegetable categories such as tuber, leafy, and non-leafy. Finally, the data were self-reported by the participants and hence subject to recall bias.

\section{Conclusions}

Our findings suggest that our questionnaire is a valid and reliable decisional balance tool for assessing the benefits and barriers of vegetable intake in adults. This tool may help guide and optimize interventions aimed at influencing vegetable consumption.

List of abbreviations

Cl: Confidence intervals; ICC: Intraclass correlation coefficients; KMO: Kaiser-Meyer-Olkin; SV: Serving

\section{Abbreviations}

Cl: Confidence intervals; ICC: Intraclass correlation coefficients; KMO: Kaiser-Meyer-Olkin; SV: Serving

\section{Declarations}

\section{Acknowledgments}

We would like to thank Naoko Shiota, Yukina Yamamoto, and Eiko Sakai for their advice. The authors wish to acknowledge the volunteers who participated in this study.

\section{Authors' Contributions}

Conceptualization: YK, JS, SN and NS; Methodology: YK, JS and NS; Software: AS; Validation: YK, SN and NS; Formal analysis: YK, JS, CK, SN, AS and NS; Investigation: YK, JS, CK, SN. AS and NS; Resources: YK, SN and NS; Data curation: NS; Writing-original draft preparation: YK and NS; Writing-review and editing: YK, SA and NS; Supervision: NS; All authors have read and agreed to the published version of the manuscript.

\section{Funding}


This work was financed by JSPS KAKENHI Grant Number 16K08900, 19 K02668.

\section{Availability of data and materials}

The datasets used and/or analyzed during the current study are available from the corresponding author on reasonable request.

\section{Ethics approval and consent to participate}

The study was performed in accordance with the Declaration of Helsinki, approved by the Ethics Committee of Kyoto Medical Center (18-095)

\section{Consent for publication}

Not applicable.

\section{Conflicts of Interest}

The authors declare no conflicts of interest associated with this manuscript.

\section{References}

1. Aune D, Giovannucci E, Boffetta P, et al. Fruit and vegetable intake and the risk of cardiovascular disease, total cancer and all-cause mortality-a systematic review and dose-response meta-analysis of prospective studies. Int J Epidemiol. 2017;46:1029-56.

2. Wang $X$, Ouyang $Y$, Liu J, et al. Fruit and vegetable consumption and mortality from all causes, cardiovascular disease, and cancer: systematic review and dose-response meta-analysis of prospective cohort studies [published correction appears in BMJ 2014, 349, 5472]. BMJ 2014;349:g4490.

3. Nanri A, Mizoue T, Shimazu T, et al. Dietary patterns and all-cause, cancer, and cardiovascular disease mortality in Japanese men and women: The Japan public health center-based prospective study. PLoS One. 2017;12:e0174848.

4. Meader N, King K, Wright K, et al. Multiple Risk Behavior Interventions: Meta-analyses of RCTs. Am J Prev Med. 2017;53:e19-30.

5. Appleton KM, Krumplevska K, Smith E, et al. Low fruit and vegetable consumption is associated with low knowledge of the details of the 5-a-day fruit and vegetable message in the UK: findings from two cross-sectional questionnaire studies. J Hum Nutr Diet. 2018;31:121-30.

6. Ministry of Agriculture, Forestry and Fisheries Food-Based Dietary Guidelines. Available online: http://www.fao.org/nutrition/education/food-based-dietary-guidelines/regions/countries/japan/en/. Accessed 1 May 2020.

7. National Institute of Health and Nutrition Outline of the National Health and Nutrition Survey Japan. 2018. Available online: https://www.mhlw.go.jp/content/000615342.pdf. Accessed on 1 May 2020. 
8. Di Noia J, Prochaska JO. Dietary stages of change and decisional balance: a meta-analytic review. Am J Health Behav. 2010;34:618-32.

9. Miller WR, Rose GS. Motivational interviewing and decisional balance: contrasting responses to client ambivalence. Behav Cogn Psychother. 2015;43:129-41.

10. Shtaynberger J, Krebs P. Associations between Decisional Balance and Health Behaviors among Adult Cancer Survivors. J Cancer Educ. 2016;31:749-54.

11. Wang DH, Kogashiwa M, Mori N, et al. Psychosocial Determinants of Fruit and Vegetable Consumption in a Japanese Population. Int J Environ Res Public Health. 2016;13:786.

12. Chuan Ling AM, Horwath C. Perceived Benefits and Barriers of Increased Fruit and Vegetable Consumption: Validation of a Decisional Balance Scale. J Nutr Educ. 2001;33:257-65.

13. Cerny BA, Kaiser HFA, Study Of A. Measure Of Sampling Adequacy For Factor-Analytic Correlation Matrices. Multivariate Behav Res. 1977;12:43-7.

14. Heo M, Kim N, Faith MS. Statistical power as a function of Cronbach alpha of instrument questionnaire items. BMC Med Res Methodol. 2015;15:86.

15. Barad A, Cartledge A, Gemmill K, et al. Associations Between Intuitive Eating Behaviors and Fruit and Vegetable Intake Among College Students. J Nutr Educ Behav. 2019;51:758-62.

16. McGuirt JT, Jilcott Pitts SB, Gustafson A. Association between Spatial Access to Food Outlets, Frequency of Grocery Shopping, and Objectively-Assessed and Self-Reported Fruit and Vegetable Consumption. Nutrients. 2018;10:1974.

17. Laforge RG, Greene GW, Prochaska JO. Psychosocial Factors Influencing Low Fruit and Vegetable Consumption. J Behav Med. 1994;17:361-74.

18. Ma J, Betts NM, Horacek T, et al. The Importance of Decisional Balance and Self-efficacy in Relation to Stages of Change for Fruit and Vegetable Intakes by Young Adults. Am J Health Promot. 2002;16:157-66.

19. Fontes de Oliveira MDC, Anderson J, Auld G, et al. Validation of a Tool to Measure Processes of Change for Fruit and Vegetable Consumption among Male College Students. J Nutr Educ Behav. 2005;37:2-11.

20. Greene GW, Fey-Yensan N, Padula C, et al. Differences in Psychosocial Variables by Stage of Change for Fruits and Vegetables in Older Adults. J Am Diet Assoc. 2004;104:1236-43.

21. Mainvil LA, Lawson R, Horwath CC, et al. Validated scales to assess adult decisional balance to eat more fruits and vegetables. Appetite. 2010;55:454-65.

\section{Figures}




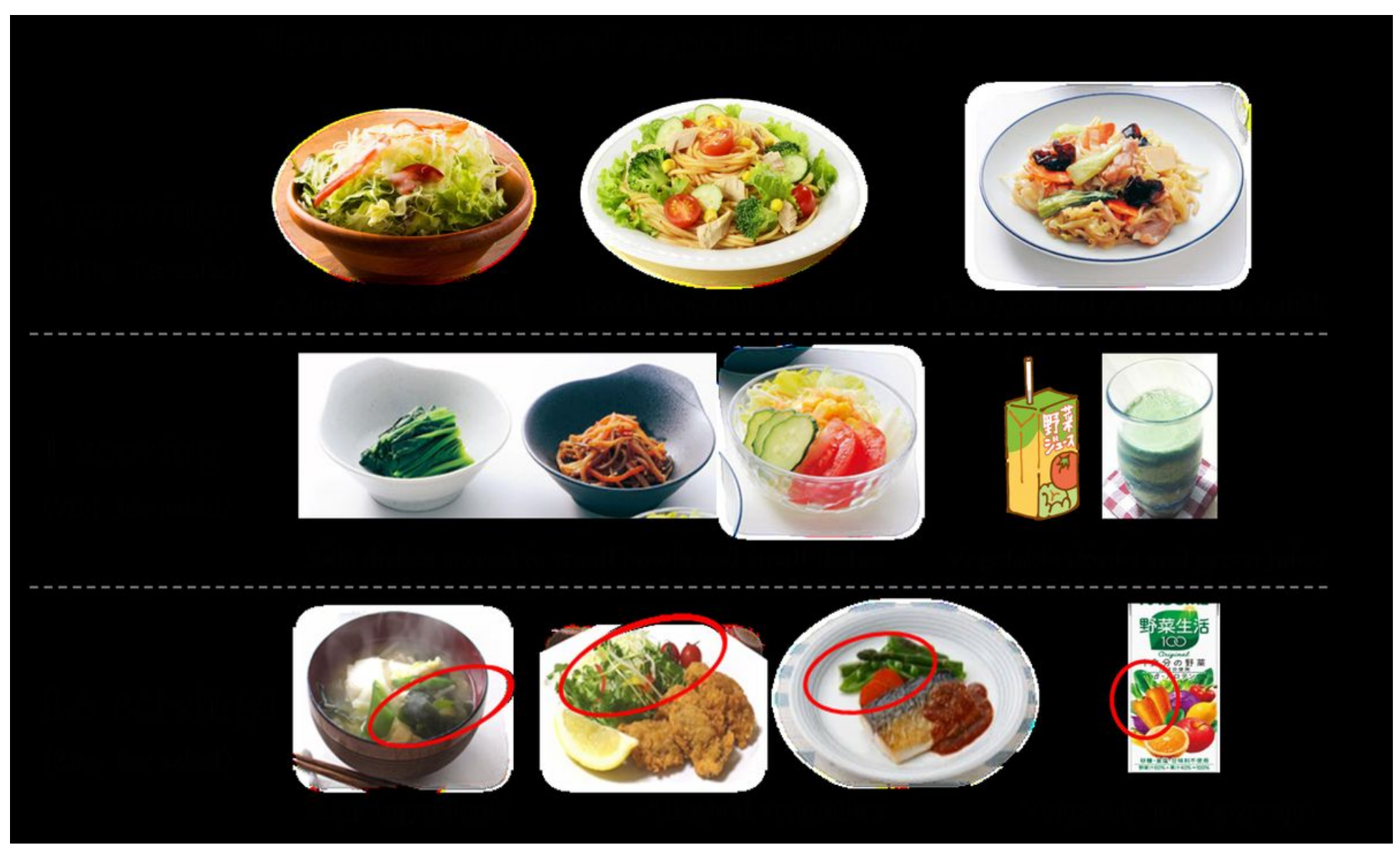

\section{Figure 1}

Number of SVs as a guide for vegetable intake.

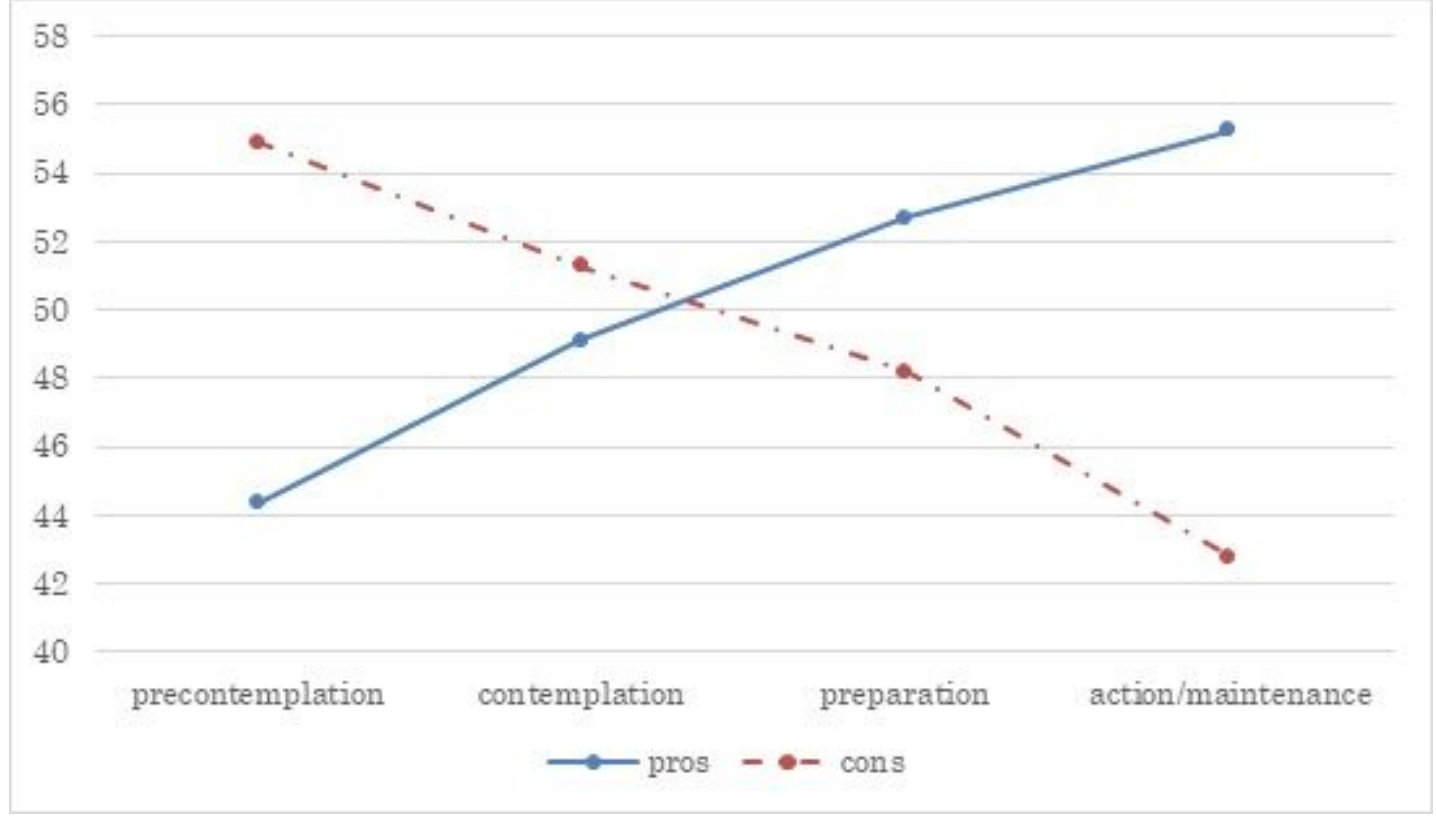

\section{Figure 2}

Pros and cons T-scores by stage of change. The scores were presented as standardized T-scores ( $\mathrm{mean}=$ $50, S D=10)$. 


\section{Supplementary Files}

This is a list of supplementary files associated with this preprint. Click to download.

- SupplementalTableS1.LikertscaleKawaguchi.docx 